\title{
The Effects of Irradiance on Translucency and Surface Gloss of Different Bulk-Fill Composite Resins: An in vitro Study
}

This article was published in the following Dove Press journal: Clinical, Cosmetic and Investigational Dentistry

\section{Abrar N Bin Nooh (D) \\ Hend Al Nahedh \\ Mohammad AIRefeai \\ Fahad AIKhudhairy}

Restorative Dental Sciences Department, College of Dentistry, King Saud University, Riyadh, Kingdom of Saudi Arabia
Correspondence: Abrar N Bin Nooh Restorative Dental Sciences Department, College of Dentistry, King Saud University, PO Box 60169, Riyadh II545, Kingdom of Saudi Arabia

Tel +966506420828

Email Abrar.nasser@hotmail.com
Purpose: The influence of different light-emitting diode (LED) curing light intensities on the translucency and surface gloss of bulk-fill resin-based composite (RBC) restorative materials was evaluated.

Materials and Methods: Forty specimens of each RBC (Filtek One bulk-fill posterior, Reveal HD bulk, Tetric N-Ceram, and Filtek Z350) were prepared. The RBCs were shaped into molds and cured using an LED curing light unit at high intensity $\left(1,200 \mathrm{~mW} / \mathrm{cm}^{2}\right)$ for 20 $\mathrm{s}$ and low intensity $\left(650 \mathrm{~mW} / \mathrm{cm}^{2}\right)$ for $40 \mathrm{~s}$. A spectrophotometer was used to determine the translucency, and a gloss meter was used to evaluate surface gloss. Data were analyzed using one- and two-way analysis of variance (ANOVA), independent $t$-test, and Tukey's and Scheffe's post hoc multiple comparison tests.

Results: The highest translucency value was observed for Reveal HD $(7.688 \pm 0.861)$ with a high curing intensity, while Filtek One showed the lowest value $(1.750 \pm 0.376)$ with a low curing intensity. The materials showed no significant difference in surface gloss with a high curing intensity. With low-intensity light curing, Filtek One showed the highest gloss value $(55.270 \pm 10.106)$, while Tetric N-Ceram and Reveal HD showed the lowest gloss values $(35.560 \pm 6.533$ and $35.680 \pm 6.648$, respectively).

Conclusion: Curing light intensity had no effect on both the gloss and translucency for all the materials tested, although for Tetric N-Ceram, higher intensity corresponded to higher gloss values while for Filtek One, higher intensity corresponded to a higher translucency value.

Keywords: curing light intensity, bulk-fill resin-based composites, translucency, surface gloss

\section{Introduction}

Optical properties such as translucency and surface gloss are some of the most important factors to consider when evaluating esthetics. In resin-based composites (RBCs), translucency indicates the color depth in the restoration. Translucency also influences the color harmony with the surrounding teeth or restoration. ${ }^{1}$ The translucency of RBCs is the result of the relationship between the resin matrix and the refractive indices of the filler particles. An increase in the difference will decrease the translucency of the material. ${ }^{2}$ On the other hand, surface gloss is an optical characteristic related to the distribution light that is reflected, scattered, and absorbed by the surface of an object. ${ }^{3}$

Commercially available bulk-fill resin composites can show adequate curing to depths of up to $4 \mathrm{~mm}^{4}$ These bulk-fill materials are synthesized with certain 
modifications in their composition to achieve this extended depth of cure, which allows increased penetration of visible light through these materials. These modifications include an increased filler size ${ }^{5}$ such as Reveal HD bulk-fill, which manufacturers claim has an HD filler technology, and a novel photoinitiator, such as the photoinitiator in Tetric N-Ceram bulk-fill composite. ${ }^{6}$ A novel monomer system found in Filtek one bulk fill, innovative Aromatic urethane dimethacrylate (AUDMA) and Addition-fragmentation monomer (AFM). Manufacturers of these bulk-fill materials claim that they show excellent optical properties such as translucency and surface gloss, both of which are influenced by the restorative material composition, ${ }^{7}$ the type of inorganic filler particles, ${ }^{8}$ distribution, index of refraction, ${ }^{9,10}$ and the thickness of the composite restoration. ${ }^{11}$

Two indices are widely used to measure translucency - the translucency parameter (TP) and the contrast ratio (CR). ${ }^{12}$ Translucency refers to the reflectance of diffused light from a surface by a turbid medium, ${ }^{13}$ and TP indicates the translucency of the resin-based composites. TP is measured by calculating the difference in the color of the resin composite over white and black backgrounds. ${ }^{12}$ In contrast, surface gloss is measured by a gloss meter with a $60^{\circ}$ angle of illumination, which measures the directed reflection and converts it to a reflectometer gloss value. $^{14,15}$ The gloss meter is a standardized and reproducible device that has been widely used to measure the surface gloss of RBCs.

As a part of efforts to improve the quality of lightcuring devices, manufacturers have developed different modes of light curing that can allow rapid curing with high irradiance. The introduction of LED light curing units (LCUs) with "high power and short exposure" has been associated with multiple controversies regarding their effectiveness, role, and safety in dentistry. ${ }^{16}$ Thus, the aim of this study was to evaluate the effects of different LED curing light intensities on the translucency and surface gloss of three bulk-fill composite resin restorative materials. The hypothesis tested was that the three bulk-fill composite resin materials would show no statistically significant effect of different irradiance levels on the translucency and surface gloss.

\section{Materials and Methods}

\section{Specimen Preparation}

A total of 160 specimens, including 40 disc-shaped specimens each of Filtek One bulk-fill posterior, Reveal HD bulk fill, Tetric N-Ceram, and Filtek Z350 (control group), were fabricated, and shade A2 was selected for all the composites except Tetric N-Ceram, for which shade IVA was used (the material compositions and manufacturer details are described in Table 1). Specimens of each material were divided into four groups, of which two groups each were used to measure translucency and gloss, and they were cured using the Bluephase N LCU (Ivoclar Vivadent, Schaan, Liechtenstein, Switzerland) at a high-intensity output $\left(1,200 \mathrm{~mW} / \mathrm{cm}^{2}\right)$ for $20 \mathrm{~s}$ or a low-intensity output $(650$ $\mathrm{mW} / \mathrm{cm}^{2}$ ) for $40 \mathrm{~s}$; the power intensity was measured using a dental Bluephase radiometer (Ivoclar vivadent, Schaan, Liechtenstein, Switzerland). For each group, ten specimens were used to measure the translucency and surface gloss. A two-part brass mold (10-mm diameter and 4-mm depth for the bulk-fill materials and 10-mm diameter and 2-mm depth was used for the conventional composite control group). After the materials were inserted into the mold, a clear Mylar strip (Mylar Uni-strip, Caulk/Dentsply, Milford, DE, USA) and a glass plate with 1.00-mm thickness were secured over it to flatten the surface and gently pressed to remove excess material on the mold.

\section{Translucency}

To measure the translucency, 20 samples of each composite were prepared, of which 10 samples were light-cured with high intensity and the other 10 underwent lowintensity light-curing. Subsequently, the specimens were stored in distilled water for $24 \mathrm{~h}$ at $37^{\circ} \mathrm{C}$ in a dark chamber.

The translucency of the specimens fabricated to the recommended thickness $(4 \mathrm{~mm})$ using the two different light cure irradiation protocols was measured with a spectrophotometer (color eye 7000 A, Model C6; GretagMacbeth, New Windsor, NY, USA) according to the CIELAB color scale relative to the standard illuminant D65 against a white background $\left(\mathrm{L}^{*}=93.26, \mathrm{a}^{*}=-0.61\right.$, $\left.\mathrm{b}^{*}=2.09\right)$ and black background $\left(\mathrm{L}^{*}=2.93, \mathrm{a}^{*}=0.38\right.$ and $\left.b^{*}=-0.34\right)$. The black standard was a matt black plate covered with black velvet, and the white standard was calibrating blocks (white and black) used according to the manufacturer's recommendation. Each specimen underwent measurements three times, after which the average value was determined.

\section{Calculation of TP}

The TP values were determined by calculating the color difference between readings over the black and white 
Table I Restorative Materials and Polishing Systems

\begin{tabular}{|c|c|c|}
\hline Brand Name & Manufacturer & Composition \\
\hline $\begin{array}{l}\text { Filtek One bulk fill } \\
\text { posterior }\end{array}$ & $\begin{array}{l}\text { 3M ESPE, St. Paul, } \\
\text { MN, USD }\end{array}$ & $\begin{array}{l}\text { Monomer matrix: aromatic urethane dimethacrylate (AUDMA), Addition-Fragmentation monomer } \\
\text { (AFM; dynamic stress-relieving monomer), I,I2-dodecane-DMA, and urethane dimethacrylate } \\
\text { (UDMA) } \\
\text { Fillers: a combination of a non-agglomerated/non-aggregated } 20 \text {-nm silica filler, a non-agglomerated } \\
\text { /non-aggregated 4-II-nm zirconia filler, an aggregated zirconia/silica cluster filler (consisting of } 20-\mathrm{nm} \\
\text { silica and 4-II-nm zirconia particles), and a ytterbium trifluoride filler consisting of agglomerate } 100- \\
\mathrm{nm} \text { particles. The inorganic filler loading is about } 76.5 \% \text { by weight ( } 58.4 \% \text { by volume). }\end{array}$ \\
\hline Reveal HD bulk fill & BISCO, USA & $\begin{array}{l}\text { Monomer matrix: urethane dimethacrylate and bisphenol A-glycidyl methacrylate (BisGMA) } \\
\text { Filler: Ytterbium fluoride }\end{array}$ \\
\hline Tetric $\mathrm{N}$ ceram & $\begin{array}{l}\text { Ivoclar Vivadent, } \\
\text { Schaan, } \\
\text { Liechtenstein }\end{array}$ & $\begin{array}{l}\text { Monomer matrix: dimethacrylates } \\
\text { Filler: Barium glass, YbF3 (prepolymer, ytterbium trifluoride), and mixed oxides } \\
\text { Filler content: } 75-77 \% \text { by wt., } 53-55 \% \text { by vol. }\end{array}$ \\
\hline $\begin{array}{l}\text { Filtek Z350 XT } \\
\text { (control) }\end{array}$ & $\begin{array}{l}3 \text { M ESPE, St. Paul, } \\
\text { MN, USD }\end{array}$ & $\begin{array}{l}\text { Monomer matrix: Bis-GMA, UDMA, TEGDMA, and bis-EMA } \\
\text { Filler: Combination of non-agglomerated/non aggregated } 20-\mathrm{nm} \text { silica filler, non-agglomerated/non- } \\
\text { aggregated 4-II-nm } \\
\text { zirconia filler, and aggregated zirconia/silica cluster filler (consisting of } 20-\mathrm{nm} \text { silica and } 4-1 \mathrm{I}-\mathrm{nm} \\
\text { zirconia particles). The inorganic filler loading is about } 72.5 \% \text { by weight ( } 55.6 \% \text { by volume). }\end{array}$ \\
\hline Sof-Lex & $\begin{array}{l}\text { 3M ESPE, St. Paul, } \\
\text { MN, USD }\end{array}$ & $\begin{array}{l}\text { Extra-thin contouring and polishing discs; aluminum oxide discs (coarse, } 92-98 \mu \mathrm{m} \text {; medium, 25-29 } \\
\mu \mathrm{m} \text {; fine, } 16-2 \mid \mu \mathrm{m} \text {; and superfine, } 2-5 \mu \mathrm{m} \text { ) }\end{array}$ \\
\hline
\end{tabular}

backgrounds for the same specimen, using the following formula:

$$
\mathrm{TP}=\left[\left(\mathrm{L}_{\mathrm{B}}-\mathrm{L}_{\mathrm{W}}\right)^{2}+\left(\mathrm{a}_{\mathrm{B}}-\mathrm{a}_{\mathrm{W}}\right)^{2}+\left(\mathrm{b}_{\mathrm{B}}-\mathrm{b}_{\mathrm{W}}\right)^{2}\right]^{1 / 2}
$$

The subscripts " $\mathrm{B}$ " and " $\mathrm{W}$ " refer to the color coordinates over black and white backgrounds, respectively.

\section{Gloss}

A total of 20 samples were obtained from each composite, of which 10 samples were light-cured with high intensity while the other 10 underwent low-intensity light-curing. The specimens were then finished and polished using a series of Sof-Lex discs for 30 s (3M ESPE, St. Paul, USA). Specimens were stored in distilled water for $24 \mathrm{~h}$ at $37^{\circ} \mathrm{C}$ in a dark chamber.

The surface gloss of each specimen was measured using a gloss meter (Novo-Curve Gloss meter, East Sussex, UK) with the light source and detector both set at $60^{\circ}$ to normal. Before measurement, the gloss meter was calibrated to a standard gloss board (Gs $\left.\left(60^{\circ}\right)=100.4\right)$. Two measurements were obtained for each specimen, and the average value was determined.

\section{Statistical Analysis}

Data were expressed as mean and standard deviation (SD) and analyzed using SPSS software (version 22.0; IBM
SPSS, Armonk, NY, USA). The results were first tested for normality using the Shapiro-Wilk test. The findings were then analyzed using two-way analysis of variance (ANOVA) followed by an independent $t$-test and one-way ANOVA. However, if one-way ANOVA showed that at least one of the materials was significantly different from the others, multiple comparison tests like Tukey's or Scheffe's post hoc test were used to determine the significant differences between the materials and curing light intensities. All tests were performed at a significance level of $\mathrm{P}<0.05$.

\section{Results \\ Translucency}

A significant effect was associated with the type of RBC $(\mathrm{F}=196.192, \mathrm{p}<0.0001)$. However, the curing light intensity $(\mathrm{F}=0.025, \mathrm{p}<0.875)$ and the interaction of $\mathrm{RBC}$ with the curing light intensity $(\mathrm{F}=1.633, \mathrm{p}<$ 0.189) did not show significance (see Table 2 for the two-way ANOVA results). With the high-intensity curing light, the TP value for Reveal HD was the highest (7.688 \pm 0.861$)$, followed by Filtek z350 (5.533 \pm 0.445), Tetric N-Ceram $(3.702 \pm 1.176)$, and Filtek One $(2.238 \pm 0.591)$ (one-way ANOVA results of the materials for each curing light intensity are listed in 
Table 2 Two-Way ANOVA for Curing Light Intensity and Material for Translucency Parameter (TP) Values

\begin{tabular}{|l|l|l|l|l|l|}
\hline Source & Type III Sum-of-Squares & df & Mean Square & F Ratio & $\boldsymbol{P}$ value \\
\hline Curing light intensity & 0.015 & I & 0.015 & 0.025 & 0.875 \\
\hline RBC & 345.178 & 3 & 115.059 & 196.192 & 0.0001 \\
\hline Curing light intensity $\times$ RBC & 2.873 & I & 0.958 & 1.633 & 0.189 \\
\hline Error & 42.225 & 72 & 0.586 & & \\
\hline Total & 2236.642 & 80 & & & \\
\hline Corrected total & 390.291 & 79 & & & \\
\hline
\end{tabular}

Abbreviation: RBC, resin-based composite.

Table 3). The multiple comparison test (Tukey) showed a significant difference among the materials $(\mathrm{p}<0.0001$ for the $F$-test).

With the low-intensity curing light, Reveal HD again showed the highest TP value (7.600 \pm 0.832$)$, followed by Filtek z350 (5.656 \pm 0.433$)$, Tetric N-Ceram (4.265 \pm 1.00$)$, and Filtek One (1.750 \pm 0.376$)$. The Tukey multiple comparison test also showed a significant difference between the materials $(\mathrm{p}<0.008$ with the $F$-test). Figure 1 presents the effect of curing light intensity on each material.
Filtek One was the only material that exhibited a significant difference between different curing light intensities. With the high-intensity curing light, Filtek One exhibited a greater TP value $(2.238 \pm 0.591)$ than that achieved with the low-intensity curing light $(1.750 \pm 0.376)(\mathrm{p}<$ $0.041)$.

\section{Gloss}

Two-way ANOVA (Table 4) indicated a significant effect associated with the type of RBC $(\mathrm{F}=6.855, \mathrm{P}<0.000)$

Table 3 One-Way ANOVA and Multiple Comparison Test (Tukey) for Translucency Parameter (TP) Values

\begin{tabular}{|c|c|c|c|c|c|c|c|c|c|c|}
\hline \multirow[t]{2}{*}{$\begin{array}{l}\text { Curing Light } \\
\text { Intensity }\end{array}$} & \multirow[t]{2}{*}{$\begin{array}{l}\text { RBC } \\
\text { Material }\end{array}$} & \multirow[t]{2}{*}{$\begin{array}{l}\text { Mean TP } \\
\text { Value }\end{array}$} & \multirow[t]{2}{*}{$\begin{array}{l}\text { Standard } \\
\text { deviation }\end{array}$} & \multirow[t]{2}{*}{$\begin{array}{l}F \text {-Test } \\
p \text {-value }\end{array}$} & \multicolumn{2}{|c|}{$\begin{array}{l}95 \% \text { Confidence } \\
\text { Interval for Mean }\end{array}$} & \multicolumn{4}{|c|}{ Multiple Comparison Test (Tukey) } \\
\hline & & & & & $\begin{array}{l}\text { Lower } \\
\text { Bound }\end{array}$ & $\begin{array}{l}\text { Upper } \\
\text { Bound }\end{array}$ & $\begin{array}{l}\text { Filtek } \\
\text { Z350 }\end{array}$ & $\begin{array}{l}\text { Filtek } \\
\text { One }\end{array}$ & $\begin{array}{l}\text { Tetric } \\
\text { N-Ceram }\end{array}$ & $\begin{array}{l}\text { Reveal } \\
\text { HD }\end{array}$ \\
\hline \multirow[t]{4}{*}{ High } & $\begin{array}{l}\text { Filtek } \\
\text { Z350 }\end{array}$ & 5.533 & 0.445 & \multirow[t]{4}{*}{0.000} & 5.215 & 5.852 & 1 & & & \\
\hline & $\begin{array}{l}\text { Filtek } \\
\text { One }\end{array}$ & 2.238 & 0.591 & & 1.815 & 2.661 & 0.000 & I & & \\
\hline & $\begin{array}{l}\text { Tetric } \\
\text { N-Ceram }\end{array}$ & 3.702 & 1.176 & & 2.861 & 4.543 & 0.003 & 0.017 & 1 & \\
\hline & $\begin{array}{l}\text { Reveal } \\
\text { HD }\end{array}$ & 7.688 & 0.861 & & 7.072 & 8.304 & 0.000 & 0.000 & 0.000 & 1 \\
\hline \multirow[t]{4}{*}{ Low } & $\begin{array}{l}\text { Filtek } \\
\text { Z350 }\end{array}$ & 5.656 & 0.433 & \multirow[t]{4}{*}{0.008} & 5.346 & 5.966 & 1 & & & \\
\hline & $\begin{array}{l}\text { Filtek } \\
\text { One }\end{array}$ & 1.750 & 0.376 & & 1.481 & 2.019 & 0.000 & I & & \\
\hline & $\begin{array}{l}\text { Tetric } \\
\text { N-Ceram }\end{array}$ & 4.265 & 1.000 & & 3.550 & 4.980 & 0.007 & 0.000 & 1 & \\
\hline & $\begin{array}{l}\text { Reveal } \\
\text { HD }\end{array}$ & 7.600 & 0.832 & & 7.004 & 8.195 & 0.000 & 0.000 & 0.000 & 1 \\
\hline
\end{tabular}




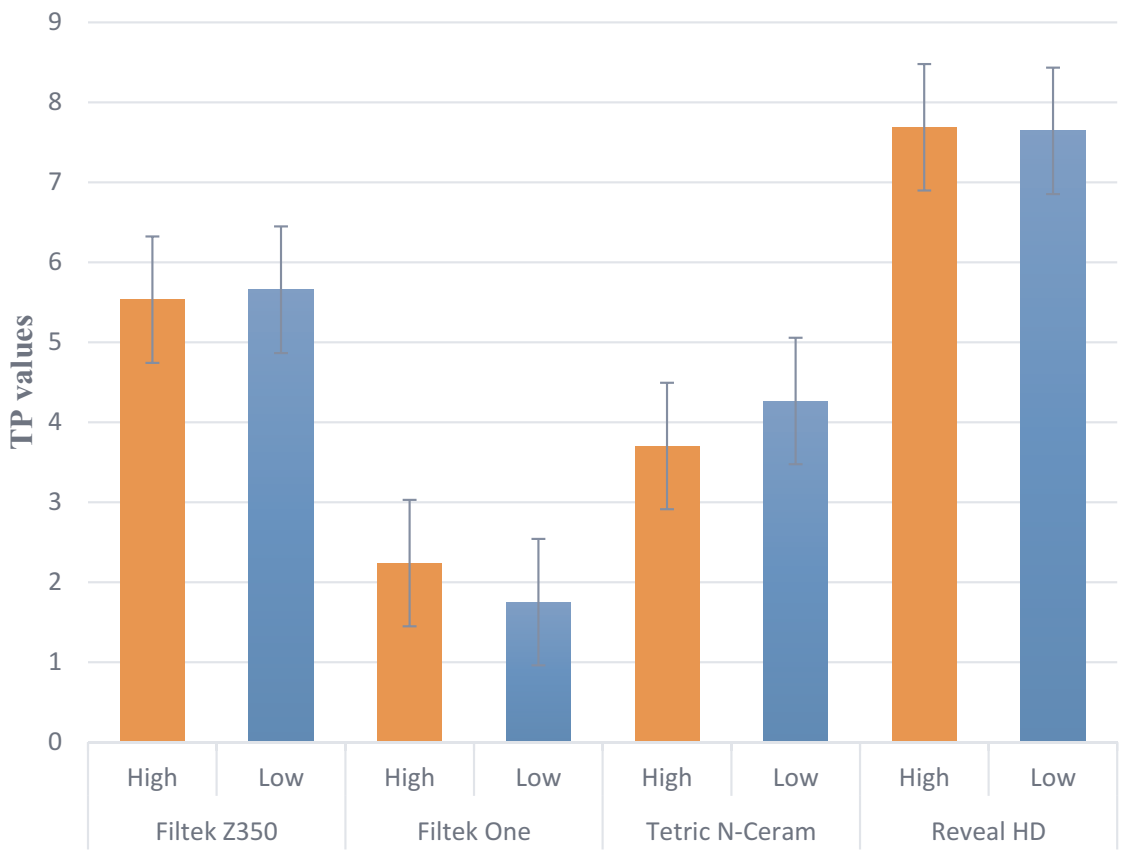

Figure I The effect of curing light intensity on translucency parameter (TP) values.

and a significant interaction of the curing light with RBCs $(\mathrm{F}=4.018, \mathrm{P}<0.011)$. However, the curing light intensity $(\mathrm{F}=0.244, \mathrm{p}<0.623)$ did not show a significant effect.

The gloss values of the RBCs were compared at low and high curing light intensities, and the gloss value of 100.4 obtained with a glass board was considered as the reference value. Thus, the shinier a surface was, the closer the value will be to $100 \%$. The results of this analysis are listed in Table 5 . With the high-intensity curing light, Tetric N-Ceram (49.100 \pm 8.548) showed the highest gloss value among all the materials, followed by Filtek z350 (46.382 \pm 11.223$)$, Filtek One (45.630 $\pm 11.223)$, and Reveal HD (35.920 \pm 9.878). The gloss values of RBCs under high-intensity irradiation were not significantly different ( $\mathrm{p}<0.136$ for the $F$-test).
However, with the low-intensity curing light, Filtek One showed the highest gloss value $(55.270 \pm 10.106)$, followed by Filtek Z350 (45.833 \pm 6.239$)$, Reveal HD $(35.680 \pm 6.648)$, and Tetric N-Ceram (35.560 \pm 6.533). There was a significant difference between the materials ( $<<0.00$ for the $F$-test), while the multiple comparison test showed significant differences between all materials except Tetric N-Ceram and Reveal HD. In addition, Tetric N-Ceram was the only material affected by the curing light intensity, with a high light intensity yielding a higher gloss value $(49.100 \pm$ 8.548) than that observed with a low light intensity $(35.560 \pm 6.533)$. The effect of curing light intensity on surface gloss of each RBC is presented in Figure 2.

Table 4 Two-Way ANOVA for the Gloss Values

\begin{tabular}{|l|l|l|l|l|l|}
\hline Source & Type III Sum-of-Squares & df & Mean Square & F-Ratio & $\boldsymbol{P}$ \\
\hline Curing light intensity & 27.474 & I & 27.474 & 0.244 & 0.623 \\
\hline RBC & 2312.848 & 3 & 770.949 & 6.855 & 0.000 \\
\hline Curing light intensity x RBC & 1355.622 & 3 & 451.874 & 4.018 & 0.011 \\
\hline Error & 8097 & 72 & 112.464 & & \\
\hline Total & 164372 & 80 & & & \\
\hline Corrected Total & 11793.39 & 79 & & & \\
\hline
\end{tabular}


Table 5 One-Way ANOVA and Multiple Comparison Test (Tukey) for the Gloss Values

\begin{tabular}{|c|c|c|c|c|c|c|c|c|c|c|}
\hline \multirow[t]{2}{*}{$\begin{array}{l}\text { Curing Light } \\
\text { Intensity }\end{array}$} & \multirow[t]{2}{*}{$\begin{array}{l}\text { RBC } \\
\text { Material }\end{array}$} & \multirow{2}{*}{$\begin{array}{l}\text { Mean } \\
\text { Gloss } \\
\text { Value }\end{array}$} & \multirow[t]{2}{*}{$\begin{array}{l}\text { Std. } \\
\text { Deviation }\end{array}$} & \multirow[t]{2}{*}{$\begin{array}{l}\text { F-Test } \\
\text { p-value }\end{array}$} & \multicolumn{2}{|c|}{$\begin{array}{l}95 \% \text { Confidence } \\
\text { Interval for Mean }\end{array}$} & \multicolumn{4}{|c|}{ Multiple Comparison Test (Tukey) } \\
\hline & & & & & $\begin{array}{l}\text { Lower } \\
\text { Bound }\end{array}$ & $\begin{array}{l}\text { Upper } \\
\text { Bound }\end{array}$ & $\begin{array}{l}\text { Filtek } \\
\text { Z350 }\end{array}$ & $\begin{array}{l}\text { Filtek } \\
\text { One }\end{array}$ & $\begin{array}{l}\text { Tetric } \\
\text { N-Ceram }\end{array}$ & $\begin{array}{l}\text { Reveal } \\
\text { HD }\end{array}$ \\
\hline \multirow[t]{4}{*}{ High intensity } & $\begin{array}{l}\text { Filtek } \\
\text { Z350 }\end{array}$ & 46.382 & 11.223 & \multirow[t]{4}{*}{0.136} & 38.353 & 54.410 & I & & & \\
\hline & $\begin{array}{l}\text { Filtek } \\
\text { One }\end{array}$ & 45.630 & 19.370 & & 31.773 & 59.487 & 0.999 & 1 & & \\
\hline & $\begin{array}{l}\text { Tetric } \\
\text { N-Ceram }\end{array}$ & 49.100 & 8.548 & & 42.985 & 55.215 & 0.965 & 0.932 & I & \\
\hline & $\begin{array}{l}\text { Reveal } \\
\text { HD }\end{array}$ & 35.920 & 9.878 & & 28.854 & 42.986 & 0.288 & 0.351 & 0.132 & 1 \\
\hline \multirow[t]{4}{*}{ Low intensity } & $\begin{array}{l}\text { Filtek } \\
\text { Z350 }\end{array}$ & 45.833 & 6.239 & \multirow[t]{4}{*}{0.000} & 41.370 & 50.296 & I & & & \\
\hline & $\begin{array}{l}\text { Filtek } \\
\text { One }\end{array}$ & 55.270 & 10.106 & & 48.041 & 62.499 & 0.039 & I & & \\
\hline & $\begin{array}{l}\text { Tetric } \\
\text { N-Ceram }\end{array}$ & 35.560 & 6.533 & & 30.887 & 40.233 & 0.022 & 0.000 & $\mathrm{I}$ & \\
\hline & $\begin{array}{l}\text { Reveal } \\
\text { HD }\end{array}$ & 35.680 & 6.648 & & 30.924 & 40.436 & 0.024 & 0.000 & 1.000 & 1 \\
\hline
\end{tabular}

\section{Discussion}

In this study, the translucency and surface gloss of bulk-fill RBCs were evaluated using two different curing light intensities. The results of this study showed that the curing light intensities had no effect on the translucency and surface gloss, except in the case of Filtek One, which showed a higher TP value with high-intensity curing, and Tetric N-Ceram, which showed a higher gloss value with high-intensity curing.

A spectrophotometer was used in this study to determine the material translucency, and Reveal HD showed

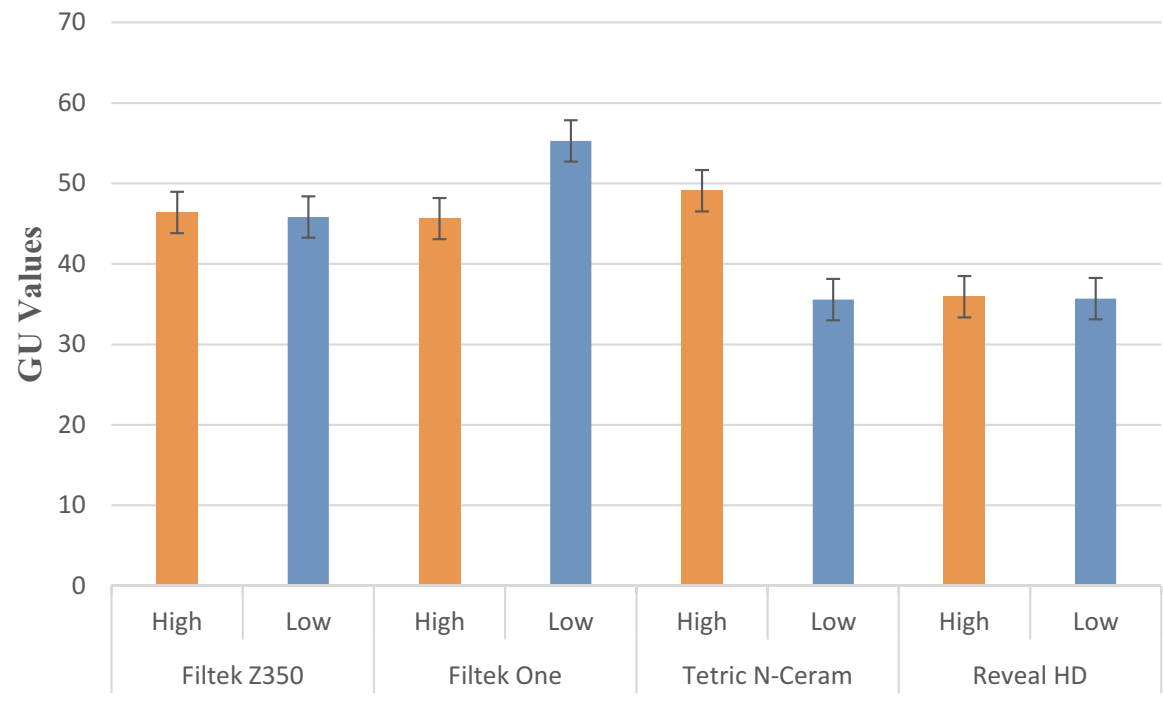

Figure 2 The effect of curing light intensity on surface gloss. 
the highest TP value. This finding could be explained by the filler-resin refractive index of the material. According to the manufacturer's literature, Reveal HD is prepared using an HD filler technology, which means that light can be effectively refracted and distributed through the material. Conversely, Filtek One showed the lowest TP, which can be attributed to the interaction of its filler with the resin matrix. This is described by the manufacturer as Smart Contrast Ratio management technology and is claimed to increase the opacity without reducing the depth of cure. Our results showed Tetric $\mathrm{N}$-Ceram to be superior in terms of opacity. This material is claimed to have a new Aessencio filler technology but, whatever the details, it proved to be superior in terms of opacity when measured experimentally.

The Filtek One bulk fill was affected by the curing light intensity, with the higher light intensity resulting in a higher TP value. This was an agreement with the results of a study by Mondelli et al ${ }^{17}$ which evaluated the changes in optical appearance in resin-based composites after light curing. The material color showed a significant change after light curing; this can be explained by the change in translucency while the material is being cured, a process called photobleaching; after light activation, photoinitiators break their chromophore groups, which diminishes their yellow color. ${ }^{18}$ Another study by Sidhu et al ${ }^{19}$ evaluated the changes in translucency caused by light-curing RBCs. They concluded that light-curing resin-based composite shows fewer changes in TP during light curing. The increased TP value could be due to the change in difference between resin matrix and that of the refractive index of the glass filler during light curing.

At a thickness of $2 \mathrm{~mm}$, Filtek Z350 showed a lower TP value than Reveal HD and a higher TP value than Tetric N-Ceram and Filtek One. The relationship between resin composite thickness and its translucency is a topic of debate. Kim et $\mathrm{al}^{20}$ evaluated the effect of resin thickness on RBC's optical properties. They found that the TP decreased with an increase in the thickness. The results of their study were in agreement with those of a study by Arimoto et al, ${ }^{11}$ and another study by Ardu et al, ${ }^{21}$ which also reported a reduction in translucency with an increase in the thickness of RBCs. Light transmission through a material with greater thickness will result in more scattering, which decreases the translucency. In our study, the highest TP values were obtained with a 4-mm-thick Reveal HD specimen; this was an agreement with the study by Son et al, ${ }^{22}$ who compared the translucency of bulk-fill and conventional composites and found that bulkfill composites had a higher translucency, they found that the lower the filler volume the higher the TP values.

Surface gloss or smoothness is one of the major esthetic features of dental biomaterials. ${ }^{23}$ Several factors affect the surface gloss, such as the restorative material composition and the finishing and polishing system used. ${ }^{10}$ Lopes et al evaluated the surface gloss using different polishing techniques and different resin-based composites. The results of their study indicated that both the finishing technique and the restorative materials influenced the surface gloss. ${ }^{24}$ The finishing and polishing procedure is an important step influencing the outcomes of the composite restoration. Many finishing and polishing materials are available on the market, such as aluminum discs, diamond burs, and rubber cups. ${ }^{25}$ In our study, finishing and polishing were performed by using a series of Sof-Lex discs. Several studies recommended using the aluminum discs, which they claimed was the best finishing and polishing protocol to be used. ${ }^{25-27}$

In the present study, Filtek One showed the highest gloss value among all the materials when using a lowintensity light cure; this could be explained by the nanofiller technology. Gerhardt et $\mathrm{al}^{28}$ found that the filler size affected the surface gloss. They concluded that a small filler size resulted in a higher surface gloss. Tetric n-Ceram was the only material effected by the curing light intensity, with a high curing light intensity resulting in a higher gloss value. However, Filtek One bulk fill, Filtek z350, and Reveal HD bulk fill were not affected by the curing light intensity. These findings were in agreement with the results of a study by Lassila et al, ${ }^{29}$ which evaluated the effect of a high curing light intensity with different curing times on the surface gloss. They concluded that the surface gloss was not affected by the different light-curing protocols used. Another study by Andrade et $\mathrm{al}^{30}$ also showed no effect of the LCU on the surface gloss of conventional RBCs.

The hypothesis in this study was partially accepted since the rest of the materials were not significantly affected by the curing light intensity. The results of this study emphasize the importance of curing light intensity and material selection. However, more longitudinal studies are needed to support the use of bulk-fill RBCs in clinical practice.

\section{Conclusions}

The curing light intensity affected the translucency of Filtek One bulk fill, with a high intensity resulting in 
a higher TP value. Similarly, Tetric N-Ceram showed a higher gloss value with high-intensity light-curing compared to that with low-intensity light-curing. However, the curing light intensity did not affect the rest of the tested materials.

\section{Acknowledgments}

The present study was registered at and approved by the College of Dentistry Research Center (Registration number: PR 0091). This manuscript is a part of a dissertation for DScD.

\section{Disclosure}

The authors report no conflicts of interest for this work and do not have any financial interest in the companies whose materials are included in this article.

\section{References}

1. Lee YK. Translucency of human teeth and dental restorative materials and its clinical relevance. J Biomed Opt. 2015;20(4):045002. doi:10.1117/1.JBO.20.4.045002

2. Kim JJ, Moon HJ, Lim BS, Lee YK, Rhee SH, Yang HC. The effect of nanofiller on the opacity of experimental composites. J Biomed Mater Res B. 2007;80(2):332-338. doi:10.1002/jbm.b.30601

3. Lee YK, Lu H, Oguri M, Powers JM. Changes in gloss after simulated generalized wear of composite resins. J Prosthet Dent. 2005;94 (4):370-376. doi:10.1016/j.prosdent.2005.08.006

4. Ilie N, Keßler A, Durner J. Influence of various irradiation processes on the mechanical properties and polymerisation kinetics of bulk-fill resin based composites. J Dent. 2013;41(8):695-702. doi:10.1016/j. jdent.2013.05.008

5. Ilie N, Stark K. Curing behaviour of high-viscosity bulk-fill composites. J Dent. 2014;42(8):977-985.

6. Moszner N, Fischer UK, Ganster B, Liska R, Rheinberger V. Benzoyl germanium derivatives as novel visible light photoinitiators for dental materials. Dent Mater. 2008;24(7):901-907. doi:10.1016/j. dental.2007.11.004

7. Azzopardi N, Moharamzadeh K, Wood DJ, Martin N, van Noort R. Effect of resin matrix composition on the translucency of experimental dental composite resins. Dent Mater. 2009;25(12):1564-1568. doi:10.1016/j.dental.2009.07.011

8. de Oliveira DCRS, de Menezes LR, Gatti A, Correr Sobrinho L, Ferracane JL, Sinhoreti MAC. Effect of nanofiller loading on cure efficiency and potential color change of model composites. $J$ Esthet Restorative Dent. 2016;28(3):171-177. doi:10.1111/jerd.12189

9. O'Brien WJ, Johnston WM, Fanian F, Lambert S. The surface roughness and gloss of composites. J Dent Res. 1984;63(5):685-688. doi:10.1177/00220345840630051601

10. Kaizer MR, de Oliveira-ogliari A, Cenci MS, Opdam NJ, Moraes RR. Do nanofill or submicron composites show improved smoothness and gloss? A systematic review of in vitro studies. Dent Mater. 2014;30(4):e41-e78. doi:10.1016/j.dental.2014.01.001

11. Arimoto A, Nakajima M, Hosaka K, et al. Translucency, opalescence and light transmission characteristics of light-cured resin composites. Dent Mater. 2010;26(11):1090-1097. doi:10.1016/j.dental.2010. 07.009

12. Johnston WM, Ma T, Kienle BH. Translucency parameter of colorants for maxillofacial prostheses. Int J Prosthodont. 1995;8(1):79-86.
13. Lee YK, Powers JM. Influence of opalescence and fluorescence properties on the light transmittance of resin composite as a function of wavelength. Am J Dent. 2006;19(5):283-288.

14. ASTM. Standard test method for specular gloss. In: Annual Book of ASTM Standards. Vol. 6. 1999.

15. Kakaboura A, Fragouli M, Rahiotis C, Silikas N. Evaluation of surface characteristics of dental composites using profilometry, scanning electron, atomic force microscopy and gloss-meter. J Mater Sci Mater Med. 2007;18(1):155-163. doi:10.1007/s10856-006-0675-8

16. Kutuk ZB, Gurgan S, Hickel R, Ilie N. Influence of extremely high irradiances on the micromechanical properties of a nano hybrid resin based composite. Am J Dent. 2017;30(1):9-15.

17. Mondelli RFL, Tavares FC, Medina-Valdivia JR, Haragushiku GA, Furuse AY, Bombonatti JFS. Color changes induced by light curing of resin composites. RSBO. 2016;13(4):241-247. doi:10.21726/rsbo. v13i4.345

18. Del Mar Pérez M, Saleh A, Pulgar R, Paravina RD. Light polymerization-dependent changes in color and translucency of resin composites. Am J Dent. 2009;22(2):97-101.

19. Sidhu SK, Ikeda T, Omata Y, Fujita M, Sano H. Change of color and translucency by light curing in resin composites. Oper Dent. 2006;31 (5):598-603. doi:10.2341/05-109

20. Kim EH, Jung KH, Son SA, Hur B, Kwon YH, Park JK. Effect of resin thickness on the microhardness and optical properties of bulk-fill resin composites. Restorative Dent Endod. 2015;40 (2):128-135. doi:10.5395/rde.2015.40.2.128

21. Ardu S, Rossier I, Di Bella E, Krejci I, Dietschi D. Resin composite thickness' influence on $\mathrm{L}^{*} \mathrm{a}^{*} \mathrm{~b}^{*}$ coordinates and translucency. Clin Oral Investig. 2019;23(4):1583-1586. doi:10.1007/s00784-018-2585-9

22. Son SA, Park JK, Seo DG, Ko CC, Kwon YH. How light attenuation and filler content affect the microhardness and polymerization shrinkage and translucency of bulk-fill composites? Clin Oral Investig. 2017;21(2):559-565. doi:10.1007/s00784-016-1920-2

23. Terry DA, Geller W, Tric O, Anderson MJ, Tourville M, Kobashigawa A. Anatomical form defines color: function, form, and aesthetics. Pract Proc Aesthet Dent PPAD. 2002;14(1):59-67; quiz 68.

24. Lopes IAD, Monteiro PJVC, Mendes JJB, Gonçalves JM, Caldeira FJF. The effect of different finishing and polishing techniques on surface roughness and gloss of two nanocomposites. Saudi Dent J. 2018;30(3):197-207. doi:10.1016/j.sdentj.2018.04.003

25. Pala K, Tekçe N, Tuncer S, Serim ME, Demirci M. Evaluation of the surface hardness, roughness, gloss and color of composites after different finishing/polishing treatments and thermocycling using a multitechnique approach. Dent Mater J. 2016;35(2):278-289. doi:10.4012/dmj.2015-260

26. Kritzinger D, Brandt PD, De Wet FA. The effect of different polishing systems on the surface roughness of a nanocomposite and a microhybrid composite. S Afr Dent J. 2017;72(6):249-257. doi:10.17159/2519-0105/2017/v72no6a1

27. Aytac F, Karaarslan ES, Agaccioglu M, Tastan E, Buldur M, Kuyucu E. Effects of novel finishing and polishing systems on surface roughness and morphology of nanocomposites. $J$ Esthet Restorative Dent. 2016;28(4):247-261. doi:10.1111/jerd.12215

28. Gerhardt K, ASQd S, Rego G, Sinhoreti MAC, Salgado VE, Schneider LFJ. Bulk and surface properties related to composite filler size. Braz J Oral Sci. 2013;12(4):323-329. doi:10.1590/S167732252013000400009

29. Lassila L, Dupont A, Lahtinen K, Vallittu PK, Garoushi S. Effects of different polishing protocols and curing time on surface properties of a bulk-fill composite resin. Chin J Dent Res. 2020;23(1):63-69.

30. Andrade KC, Pini NI, Moda MD, et al. Influence of different light-curing units in surface roughness and gloss of resin composites for bleached teeth after challenges. J Mech Behav Biomed Mater. 2020;102:103458. doi:10.1016/j.jmbbm.2019.103458 


\section{Publish your work in this journal}

Clinical, Cosmetic and Investigational Dentistry is an international, peer-reviewed, open access, online journal focusing on the latest clinical and experimental research in dentistry with specific emphasis on cosmetic interventions. Innovative developments in dental materials, techniques and devices that improve outcomes and patien satisfaction and preference will be highlighted. The manuscript management system is completely online and includes a very quick and fair peer-review system, which is all easy to use. Visit http://www.dovepress.com/testimonials.php to read real quotes from published authors. 